\title{
Correction to: Performance of a bioglass-based dentine desensitizer under lactid acid exposition: an in-vitro study
}

Andrea Stefanie Manz, Thomas Attin, Beatrice Sener and Philipp Sahrmann ${ }^{*}$

\section{Correction to: BMC Oral Health \\ https://doi.org/10.1186/s12903-018-0642-z}

Following publication of the original article [1], the authors reported their family and given names have been mismatched. The correct names can be found below:

Given name: Andrea Stefanie

Family Name: Manz

Given name: Thomas

Family Name: Attin

Given name: Beatrice

Family Name: Sener

Given name: Philipp

Family Name: Sahrmann

The publisher apologizes for any inconvenience caused by this error.

Received: 17 July 2019 Accepted: 17 July 2019

Published online: 24 July 2019

\section{Reference}

1. Stefanie, et al. Performance of a bioglass-based dentine desensitizer under

lactid acid exposition: an in-vitro study. BMC Oral Health. 2018;18:193.

https://doi.org/10.1186/s12903-018-0642-z.

\footnotetext{
* Correspondence: philipp.sahrmann@zzm.uzh.ch

Clinic for Preventive Dentistry, Periodontology and Cariology, Center of

Dental Medicine, University of Zurich, Plattenstr. 11, 8032 Zurich, Switzerland
} 